\title{
O MANUAL DIDÁTICO E OS QUADROS MURAIS NA RELAÇÃO EDUCATIVA DO CURSO NORMAL SAGRADO CORAÇÃO DE JESUS - 1936-19711
}

\author{
Sandino Hoff \\ Universidade Tuiuti do Paraná \\ sandino.hoff@terra.com.br \\ Armindo José Longhi \\ Universidade do Contestado/Campus de Canoinhas \\ armindo@cni.unc.br \\ Maria Angélica Cardoso \\ Universidade Estadual de Campinas \\ cardosoangelica@terra.com.br
}

\section{RESUMO:}

Este estudo investigou os instrumentos do trabalho didático utilizados no Curso Normal do Colégio Sagrado Coração de Jesus de Canoinhas, SC, entre 1936 e 1971, no intuito de verificar como se realizou a formação cristã em meio à proposta oficial de uma formação laica. Inquiriu: os documentos existentes no arquivo do colégio; o livro Crônica, que registrou os momentos relevantes da vida das Irmãs; alguns textos de alunos, editados no Órgão das Normalistas; depoimentos da ex-diretora, de ex-alunos e de ex-professores. A investigação concluiu que o espaço da proposta pedagógica cristã, em meio às obrigações das diretrizes laicas do Estado, foi conquistado mediante o uso dos instrumentos didáticos: o manual didático e o quadro mural. Esses recursos didáticos cumpriram a função social e religiosa de uma vigilância metodológica na transmissão dos saberes escolares, pois, cumprindo as normas governamentais, foram subsumidos ao domínio do professor na prática escolar.

Palavras-Chave: Organização do trabalho didático, Instituições Escolares e Práticas Escolares.

\section{MANUAL TEACHING AND TABLES WALL RELATIONSHIP IN NORMAL COURSE OF EDUCATION SACRED HEART OF JESUS - 1936-1971}

\begin{abstract}
:
This study investigated the tools of the teaching course used in the Normal College Sagrado Coração de Jesus, State of Santa Catarina, between 1936 and 1971 in order to see how to place the Christian formation in the midst of an official proposal of secular education. Inquired the documents in the archive of the college, the book Chronicle, which posted the material times the life of the Sisters, some texts of students, published in the Organ of Normalists; testimony of the former director of alumni and former teachers. The investigation concluded that the space of pedagogical Christian, among the obligations of the guidelines of the secular state was achieved through the use of teaching tools: the textbook and the mural. These teaching resources met the social and religious function of a surveillance methodology in the transmission of school knowledge, thus complying with Revista HISTEDBR On-line, Campinas, número especial, p. 128-144, mai.2010 - ISSN: 1676-2584 128
\end{abstract}


government regulations, have been subsumed into the domain of the teacher in school practice.

Keywords: Organization of the teaching work, Educational institutions and School Practice.

\section{INTRODUÇÃO}

Este estudo investigou o manual didático e o quadro mural utilizados no Curso Normal Sagrado Coração de Jesus - CNSCJ de Canoinhas, 1936-1971, instrumentos didáticos que deram forma a uma peculiar organização do trabalho didático. Conforme Alves, (2005, p. 10-11) a acepção conferida à forma histórica de organização do trabalho didático envolve os seguintes aspectos: ela é uma relação educativa que se dá num espaço físico determinado e se realiza com a mediação de recursos didáticos para a transmissão do conhecimento.

Por instrumento do trabalho didático, entendemos "os recursos didáticos, envolvendo os procedimentos técnico-pedagógicos do educador e as tecnologias educacionais; fazem a mediação entre o professor e os conteúdos programados para serem transmitidos aos alunos". Por relação educativa, entendemos "a organização que coloca, frente a frente, uma forma histórica de educador, de um lado, e uma forma histórica de educando, do outro" (ALVES, 2005, p. 10-11).

Para desvelar o caráter histórico do CNSCJ, associamos a relação educativa a dois instrumentos didáticos: a prática escolar referida ao uso do livro e à utilização de quadros murais. Dessa maneira, revelamos a função social que exerceram essas duas práticas escolares no âmbito do Curso Normal.

O colégio teve origem, quando na região, arrefeceu-se o agressivo impulso desenvolvimentista dos grupos monopólicos, apoiados pelo Estado Intervencionista. Como conseqüência da ação dos monopólios Lumber (Três Barras, 1908), Farkuhar (Vale do Rio do Peixe, 1907), Companhia Colonizadora de Hamburgo (desde 1849 em Joinville e no Planalto Norte em 1873) e Companhia Industrial Catarinense (Canac, Abdon Baptista e outros, em Joinville, São Bento e Canoinhas, entre 1891 e 1914), vários eventos abalaram a tranquilidade social no Norte, Planalto Norte e Meio Oeste do estado de Santa Catarina, assim listados: sertanejos e caboclos foram expropriados das terras de cultivo, da madeira e dos ervais nativos, sofrendo um processo de subsunção real ao capital; a Questão dos Limites acarretou escaramuças violentas e, somente em 1916, ficou acordada entre os dois estados; a Guerra dos Caboclos entre 1912 e 1916, quando foram dizimadas milhares de pessoas e mais de quatro mil, conforme depoimento do vigário de Canoinhas, Frei Menandro Kamps (1969, p. 2), entraram na cidade, maltrapilhos e emagrecidos. Além disso, acontecimentos econômicos atingiram a região: a venda da Cia. Industrial Catarinense e do Grupo Farkuhar a vários grupos no final da década de 1910 e o consequente investimento do lucro, auferido com a venda, no capital financeiro; o crack de Nova York (1929); a encampação do grupo Lumber pelo governo brasileiro, na década de 1940; e o fim da produção da erva-mate na região (1932)2.

Após esses acontecimentos, a região ficou, momentaneamente, nas mãos de pequenas e médias empresas e de pequenas propriedades rurais de trabalho familiar. $\mathrm{O}$ município de Canoinhas ainda mantinha a economia com um grande volume de produção de erva-mate e de madeira, quando, a partir de 1932, outras regiões haviam diminuído drasticamente a produção. 
É nesse período de paz, propício para o trabalho e para o progresso individual e social, expresso pela Irmã Cármen na frase: "uma vez serenados os ânimos", que, em 1921, nasceu o Colégio Sagrado Coração de Jesus para formar crianças e jovens a fim de que pudessem "ser pessoas livres e agentes de transformação social" (WELTER, 2006, p. 889). Nessa espécie de "Pax Romana", nasce o cristianismo escolar na cidade de Canoinhas. Instalam-se sucessivamente o Primário, (1921) o Pré e o Jardim de Infância (1928), o Curso Fundamental (1932) e, em 1936, o CNSCJ, sob os princípios do cristianismo, formando um conjunto unitário de ensino e de formação de professores, com a denominação de Instituto de Educação, auferida pelo governo catarinense.

A sociedade de classe média, baseada no trabalho familiar de imigrantes e nos pequenos e médios negócios, recebeu da parte das igrejas cristãs o nome de comunidade. Esta exigiu a educação escolar para seus filhos e a formação de professores para as escolas rurais e as escolas localizadas nas pequenas cidades da região e de outros estados. Trabalho não faltava para os professores formados. Quando, em 1938, por ocasião da nacionalização do ensino, foram fechadas 298 escolas de língua estrangeira, o governo construiu 472 novas escolas no Estado de Santa Catarina, atendendo à população. $\mathrm{O}$ aumento de escolas não correspondeu ao aumento de professores habilitados, como Teive (2002, p. 168) observa, referindo-se a duas décadas após: "No que tange ao professor, à sua formação, o quadro não era menos desalentador: 5.500 das 9.000 professoras de $1^{\mathrm{a}} \mathrm{a} 4^{\mathrm{a}}$ séries existentes no Estado, no ano de 1960, não estavam habilitadas".

A formação de professores para as escolas ficou a cargo das instituições religiosas no Planalto Norte e no Meio Oeste, nas décadas de 1930 a 1960. O Curso Normal Sagrado Coração de Jesus também assumiu essa tarefa. A relação educativa foi instituída mediante instrumentos de trabalho didático que cumpriram a função de atuar conforme as prescrições dos programas do governo catarinense e conforme a proposta pedagógica do colégio confessional. As duas visões conviveram na relação educativa que se deu no mesmo espaço escolar.

Fazer o Curso Normal exigia sacrifícios dos pais com o pagamento das mensalidades e com a compra de livros e de materiais. Inicialmente, a especialização dos instrumentos de ensino recaiu no manual. As professoras do CNSCJ exigiram dos alunos a compra de livros e de materiais, como condição de matrícula. A lição de aula pertenceu ao comando da professora, que submetia a segundo plano os manuais prescritos. Estes eram lidos como tarefa de casa e, na exposição da matéria, a irmã docente explicava o conteúdo programado pelo manual e o debatia com os alunos. A exigência da compra de livros tornou-se inviável economicamente e, em 1965, quando foi criada a Província brasileira, as irmãs suíças, ainda vivas, retornaram a sua pátria e as irmãs brasileiras assumiram a administração da congregação e do colégio, o quadro mural substituiu totalmente o livro nas lições do CNSCJ. Nesse momento, o barateamento dos serviços educacionais ficou sensível para os pais dos alunos. O Curso Normal especializou-se na produção de quadros murais, - gravuras e, principalmente, cartazes - menos dispendiosos do que os livros. A eles coube a função de garantir a centralização da lição no professor e a transmissão do conhecimento e dos conteúdos formativos cristãos. Tanto o livro explicado pela professora, quanto a gravura e o cartaz, na prática escolar do curso, caracterizavam o ideal das irmãs que era formar professores na técnica e na prática do magistério, a partir de sua proposta pedagógica.

A institucionalização da Escola Normal SCJ e a história da formação de professores estão registradas nos Arquivos do Curso Normal do Sagrado Coração de Jesus, num total de 16 caixas. Ali, encontramos leis, decretos, regulamentos, regimentos, atas de exames

Revista HISTEDBR On-line, Campinas, número especial, p. 128-144, mai.2010 - ISSN: 1676-2584 130 
finais, exame oral e escrito, quadros curriculares, disciplinas, certificados de conclusão do curso, registro de diplomas, boletins de alunos, pastas de alunos, registros de notas, conteúdos de disciplinas, rigorosamente iguais aos prescritos, livros de matrículas e uma reduzidíssima produção discente de 11 textos de normalistas editados em manuscrito no $\mathrm{n}^{\mathrm{o}}$ 9, 1946, do Órgão das Normalistas.

A dificuldade em reunir traços manuscritos das atividades dos professores e da produção dos alunos, comum nos estabelecimentos de ensino, também se constatou no CSCJ. Héry (1999, p. 12) e Catteeuw (2005) lastimam a ausência de uma política de conservação documental. Todo historiador gostaria ter mais documentos em mãos a fim de diminuir o silêncio sobre o cotidiano, sobre as lutas pelo predomínio da educação cristã e sobre as contradições sociais que ecoavam necessariamente no colégio. Julia (2001, p. 17) adverte não exagerarmos o silêncio dos arquivos, justificando sua idéia: "O historiador sabe fazer flechas com qualquer madeira". Contudo, o historiador da educação deve lembrar, também, o argumento do renascentista Policiano: "Uma estátua de Mercúrio não sai de qualquer tronco". (HOFF, 1996, p. 9).

Algumas redações de alunos constituem exemplares isolados, confiadas à pesquisa pela irmã Cármen. O arquivo está bem conservado no que concerne a documentos de guarda obrigatória; reduzido quanto às práticas escolares. Delas, realizamos uma reconstituição lacunar, à base de fontes e de entrevistas. O zelo da irmã permitiu conservar algumas fontes que se estendem além do arquivo oficial. Não encontramos relatos de experiências, assinatura de revistas ou leitura nelas realizada, nem correspondências. A soma de leitura que realizamos dos documentos começou a compor e reconstituir parte daquele passado. Os dados começaram a fazer sentido nas releituras feitas dos documentos, apesar de isolados e incompletos. As lacunas documentais não impedem uma análise satisfatória do Curso Normal SCJ.

De considerável valor foi uma rápida leitura permitida da Chronik der Filiale Canoinhas (Crônica da Filial de Canoinhas), uma espécie de livro do tombo que registrou os principais assuntos e eventos da congregação. Trata-se de um manuscrito, escrito em alemão, pois, as irmãs suíças provinham dos cantões de língua alemã. A Crônica foi escrita em língua portuguesa a partir de 1943 e datilografada a partir de 1950. Os registros seguem o calendário anual. A casa das religiosas, também, era o lugar do domínio do conhecimento e o ambiente físico e acadêmico dos planejamentos da escola, das disciplinas e da administração da instituição educacional. Assim, vários assuntos específicos da Crônica estendem-se às referências com o Curso Normal Sagrado Coração de Jesus. O livro apresenta-se em curso contínuo desde 1920. Nele encontram-se algumas valiosas informações sobre o dia a dia do colégio e do Curso Normal.

Em nosso estudo, que tem o limite temporal compreendido entre 1936 e 1971, formamos dossiês de ex-professores e ex-alunos. Os depoimentos revelaram-se importantes para reconstituir as práticas escolares efetuadas mediante o instrumento didático utilizado no Curso Normal para ministrar as lições.

A mediação do livro didático posicionou a relação educativa na pessoa da professora que, no período estudado, também era religiosa. A obrigatoriedade de o aluno ter em mãos o manual não significou que fosse utilizado como fonte principal dos conhecimentos. A relação educativa, entre 1936 e 1965, ocorreu centrada no professor. O livro ficou subordinado ao discurso da professora. No período que vai de 1965 a 1971, os quadros murais - gravuras, figuras e cartazes - exerceram a função subalterna, posto que de grande visibilidade, antes cumprido pelo livro. No entanto, o controle da lição permaneceu nas mãos da professora.

Revista HISTEDBR On-line, Campinas, número especial, p. 128-144, mai.2010 - ISSN: 1676-2584 131 
Este estudo centra sua idéia principal em dois pilares: o manual, utilizado na transmissão de conhecimentos, estava subordinado ao discurso do professor que explicava o conteúdo; isso entre 1936 e 1965. No período de 1965 a 1971, predominaram amplamente os murais - gravuras e, principalmente, cartazes, - como recursos técnicos do ensino. A opção por esses instrumentos teve sua razão de ser.

\section{CAMINHOS PARA ADENTRAR NO CURSO NORMAL SAGRADO CORAÇÃO DE JESUS}

O Colégio Sagrado Coração de Jesus realizou uma unidade cultural e uma relação educativa num espaço físico, com especificidades próprias e apropriadas aos cursos planejados. Criou o curso de formação de professores - a singularidade de nosso estudo para atender a região constituída de pequena propriedade rural e de pequenos negócios a expressar o desenvolvimento particular da região, após os monopólios terem diminuído e, até, abandonado suas atividades na região.

A identidade que marca o CNSCJ liga-o aos demais cursos normais porque as linhas gerais são comuns. Os Institutos de Educação, as idéias e as práticas de ensino efetivadas pelos assinantes do Manifesto dos Pioneiros da Educação Nova impuseram a referência para a educação escolar brasileira e para a formação de professores do país. $\mathrm{O}$ CNSCJ identificou-se com os demais cursos, deles se aproximou e efetuou no colégio as linhas gerais do processo de formação de professores, comuns à educação catarinense. A equiparação dos cursos normais de estabelecimentos confessionais à escola normal pública foi um dos pontos de reivindicação dos bispos católicos e havia sido realizada no governo Nereu Ramos em 1935, um ano antes da instalação do Curso Normal do Sagrado Coração de Jesus. Em outros termos, todos os cursos normais de SC seguiram, oficialmente, as diretrizes públicas. A investigação científica expressou a unidade cultural predominante entre os cursos normais, todos sob a égide de desenvolvimento sócio-econômico brasileiro, conforme afirmações dos pioneiros da educação nova. Estes seguiam o pensamento educacional europeu e norte-americano porque ligado ao desenvolvimento da produção de bens, a exigir dirigentes e população com formação científica. Tem-se aqui expressão universal que submeteu os cursos de formação de professores a linhas gerais comuns.

A constituição de monopólios em SC, que permitiram o desenvolvimento regional durante décadas anteriores e posteriores à do século XX, não se sustentou após todas as crises. As grandes empresas abandonaram a atividade produtiva na região e aplicaram o dinheiro da venda das indústrias no capital financeiro, mantendo, de outra forma, o controle sobre o desenvolvimento sócio-econômico $\mathrm{O}$ caminho das pequenas empresas, após o Acordo dos Limites e após a Guerra dos Caboclos, reorganizou o desenvolvimento do Planalto Norte e do Meio Oeste de Santa Catarina. As pequenas propriedades rurais, junto com as pequenas e médias empresas, firmaram o ambiente sócio-econômico o que proporcionou as condições e o caminho da organização do colégio confessional. Em 1920, as irmãs missionárias de Maria Auxiliadora, ao iniciar os preparativos para implantar o colégio, o fizeram para atender essa necessidade social.

A pesquisa inquiriu as atividades educacionais como uma singularidade de organização do trabalho didático em documentos e em depoimentos e entende que a unidade cultural e a relação educativa, efetivadas no CNSCJ, são únicas, próprias, singulares. Configuram as operações práticas no espaço educativo, facilitadas pelas condições particulares do desenvolvimento regional e são expressão, em sua singularidade, da universalidade das tendências educacionais.

Revista HISTEDBR On-line, Campinas, número especial, p. 128-144, mai.2010 - ISSN: 1676-2584 132 
Dessa forma, os eixos da pesquisa investigaram os nexos entre o singular e o universal existentes em cada um dos aspectos que envolveram a organização do trabalho didático. Isso porque singular e universal são indissociáveis. A simples conferência das introduções a capítulos do livro As escolas normais no Brasil, organizado por Araújo e outros (2008) possibilita encontrar determinantes comuns na formação institucionalizada de professores primários, impostos por modelos avançados de educação, estabelecidos no centro do país e capturados dos Estados Unidos e da Europa. No início do século XX, houve a tentativa de dar um aspecto unitário à educação escolar brasileira, como foi o caso dos grupos escolares e, na década de 1930, do Instituto de Educação que reunia o jardim de infância, os grupos escolares, os cursos secundários, o curso normal e o ensino superior num só prédio. Essa dinâmica estrutural tinha a ver com o desenvolvimento sócioeconômico do país, afirmavam os próprios intelectuais da proposta, ou no dizer de Lourenço Filho (2002, p. 64):

É preciso considerar que a expansão dos sistemas escolares, em quase toda a Europa e vários países da América e da Ásia, não se dava ao simples arbítrio dos governantes. Concorriam para ela razões políticas por expansão das idéias democráticas e outras derivadas de transformações da vida econômica. $\mathrm{O}$ trabalho industrial começava a modificar muitas regiões.

A realidade do CNSCJ estabeleceu nexos com os determinantes estaduais, nacionais e internacionais, estes últimos por conta não só das irmãs suíças que administravam o colégio, mas também, por conta do movimento renovador da educação, do qual fez parte Lourenço Filho, Anísio Teixeira e Fernando de Azevedo e, em solo catarinense, João Roberto Almeida, Sodieck, Trindade e Elpídio Barbosa.

Seis anos antes da criação do SCJ, ao final da Guerra do Contestado, quatro mil caboclos miseráveis adentraram em Canoinhas. Essa história e todas as histórias de violência foram esquecidas. A população não se referia aos acontecimentos do passado Questão dos Limites, Guerra dos Caboclos, Monopólios - e a escola, no período estudado, não ensinava a história dos catarinenses e paranaenses referentes a esses temas. Em contrapartida, o progresso tomou conta da consciência da população. Por vários anos, Canoinhas foi responsável por $50 \%$ da produção de erva-mate em SC. A cidade já era cortada pela via férrea. A encampação da Lumber pelo governo federal, a partir de 1940, criou vantagens competitivas para as pequenas empresas.

A clientela do CNSCJ proveio de uma categoria social, à qual pertenciam comerciantes, industriais, profissões liberais, funcionários públicos, executivos e, também, agricultores mais bem situados economicamente. Essa população era mais alfabetizada do que o conjunto da população. O município e a região abrigavam centenas de famílias de origem ucraniana, austríaca, polonesa e alemã a exigir educação escolar para seus filhos.

À tradição católica das famílias colocava-se a necessidade social de formação religiosa nas escolas.

\section{AS CIÊNCIAS DE REFERÊNCIA: O RELIGIOSO E O LAICO}

Em 1935, o governo catarinense realizou a primeira das duas reformas principais da década. O Decreto-Lei 713, janeiro de 1935, transformou as Escolas Públicas de Florianópolis e de Lages em Institutos de Educação e concedeu a equiparação das Escolas Normais confessionais às publicas. O mesmo decreto instituiu Escola Normal Primária, em nível de Curso Complementar, com duração de três anos, continuando o objetivo principal

Revista HISTEDBR On-line, Campinas, número especial, p. 128-144, mai.2010 - ISSN: 1676-2584 133 
de formar professores para as escolas isoladas. O CNSCJ não implantou essa modalidade de ensino. O decreto-lei, também, dotou a Escola Normal Secundária com duração de três anos, modalidade instituída pelo CNSCJ em 1936.

A reforma de 1935 deu destaque, pela primeira vez no Estado, à Sociologia como disciplina acadêmica, na perspectiva de cientifização da formação dos professores, vinculando-a às ciências consideradas Fontes da Educação: Biologia, Psicologia, Filosofia, História e a própria Sociologia (DAROS, 2002, p. 47). As Ciências Fontes da Educação, introduzidas nos Cursos Normais, fundaram-se na teoria de Durkheim, nas obras de Lourenço Filho, Fernando de Azevedo e na revista Estudos Educacionais. Esta foi um "periódico que representou um espaço de reconhecimento e expansão da identidade social dos intelectuais-educadores catarinenses, como João Roberto Moreira e Henrique Stodieck". (NASCIMENTO; DANIEL, 2002, p. 63).

Em 1939, o Decreto-lei n. 306 reorganizou o Instituto de Educação. Criou o Curso Fundamental de cinco anos, de nível secundário e preparatório para o Curso Normal, estabelecido com duração de dois anos, exigindo-se o secundário como condição para o ingresso. O Decreto compôs o currículo do Curso Normal que foi seguido por todos os cursos normais, públicos ou confessionais de Santa Catarina e organizou o Pré-Primário (3 anos), o Primário (4 anos), o Fundamental (5 anos) e o Normal (2 anos). As reformas de 1935 e de 1939 introduziram mais fortemente do que em 1910 as chamadas Ciências Fontes da Educação nos currículos catarinenses, habilitando os professores no método e no conhecimento científico.

O Curso Normal Secundário do Sagrado Coração de Jesus regeu-se, posteriormente, pelo Decreto 306, de 1939. Um dos pré-requisitos para o ingressante no curso era ter cursado cinco anos do Ciclo Fundamental. O total da formação de professores estava composto com 4 anos de Primário, 5 anos de Fundamental e, depois, 2 anos de Normal.

O Estado Novo havia implementado o processo de nacionalização do ensino, como ideal de modernidade. O governo do Interventor Federal em Santa Catarina Nereu Ramos (1937-1945) tomou várias decisões nesse sentido, entregando à escola uma parcela da responsabilidade de preparar os catarinenses, por meio de uma legislação, pautada em princípios definidos, a fim de que as disciplinas tivessem uma postura científica e racional. Promoveu a reestruturação no aparelho educacional, a fim de adequar o currículo e as disciplinas aos principais pressupostos filosóficos, sociológicos, psicológicos e pedagógicos do movimento brasileiro de renovação educacional. No estado de Santa Catarina e nos demais estados sulinos intensificou-se a questão da nacionalização do ensino por ser região em que habitavam muitos descendentes europeus. O governo proibiu o uso da língua estrangeira nos estabelecimentos escolares, em 1938, e criou a Superintendência Geral das Escolas Particulares e Nacionalização do Ensino. A necessidade de nacionalizar as escolas estrangeiras fez com que as atividades educacionais fossem acompanhadas por inspetores escolares. No primeiro período de funcionamento do CNSCJ, todos os documentos encontram-se aprovados pela assinatura do inspetor escolar.

Com os renovadores da educação catarinense - Almeida, Trindade e Stodieck - as Ciências Fontes da Educação são chamadas a dizer a verdade sobre a criança e sobre a finalidade social da educação escolar. Segundo NÓBREGA (2003, p. 256), "os modernos processos pedagógicos - o método intuitivo ou lição das coisas - são identificados como científicos, tendo como base a observação e a exploração da percepção dos órgãos dos sentidos - como conceberam Froebel e Pestalozzi”. 
Os programas das disciplinas de Psicologia Educacional e de Pedagogia foram estabelecidos por João Roberto Moreira, o então professor catedrático dessas matérias no Instituto de Educação da capital catarinense. O programa de Sociologia Educacional foi elaborado por Henrique Stodieck, professor titular dessa cadeira no Curso Normal desse mesmo Instituto pelo método da escola ativa, o método que fizesse partir o ensino dos fatos particulares e os elevasse às idéias gerais. As disciplinas científicas tinham o objetivo de operar sínteses dos fatos sociais e de reconstituir a unidade do conhecimento, de forma precisa, identificável e racional. A escola seria uma réplica da sociedade, mais simplificada, mais ordenada e mais homogênea. Conforme os renovadores da educação, a cultura generalista não daria conta desse objetivo.

Daros (2002, p. 41) esclarecem a introdução das disciplinas científicas:

Dentre os conteúdos discutidos como necessários à formação dos professores, destacam-se os de sociologia, que junto com os de biologia, psicologia, história e filosofia da educação, vieram a formar o que posteriormente se denominou "Fundamentos da Educação".

As disciplinas científicas davam sustentação à Pedagogia no tocante às propostas de intervenção na prática educacional.

A cúpula religiosa da Igreja Cristã Católica não via com bons olhos a renovação educacional baseada na racionalidade científica. Fiel à tradição de uma educação generalista, jogou seus bispos e leigos na luta contra o movimento renovador. $\mathrm{O}$ rol de produções acadêmicas e seus autores foram apontados no Primeiro Congresso Católico de Educação, realizado no Rio de Janeiro, em 1934, como responsáveis pela difusão dos "excessos da Pedagogia Moderna". Contra os excessos dos renovadores da educação, os congressistas católicos opuseram a doutrina dos mestres católicos renovadores. Alceu Amoroso Lima, líder católico e sociólogo, foi incumbido de barrar as inovações dos Pioneiros da Educação Nova. Daí, a tentativa de estratégias a respeito da Escola Nova e do papel da Sociologia que configurasse uma pedagogia cristã na formação de professores. Ambos, porém, católicos e renovadores compartilhavam um objetivo comum: "a educação como formação da nacionalidade". A luta se dava pelo controle ideológico do aparelho escolar e pela organização da cultura. Interessante foi verificar que a educadora Maria Junqueira Schmidt, a despeito de fazer parte do grupo de "pedagogos modernos", tornou-se conselheira assídua do colégio3.

A Igreja Cristã Católica, desde a Proclamação da República, quando se deu a separação da Igreja do Estado, lutou com o Estado pelo controle sobre a formação de dirigentes. Instituiu nas escolas confessionais a vigilância metodológica na transmissão do conhecimento e dos conteúdos formativos da pessoa humana.

Separada do Estado, em 1889, a Igreja buscou uma reaproximação em novas bases, procurando assegurar sua autonomia no poder público. Seguindo rigorosamente os ensinamentos constantes da encíclica Rerum Novarum de 1891, o clero brasileiro elegeu a difusão da doutrina cristã como instrumento de afirmação social e política frente ao Estado no intuito de que o Estado abrigasse suas instituições contra o perigo do laicismo que acompanhou o advento da modernidade. Daí, o cuidado com o cultivo do conhecimento, dos livros aprovados e da autorização das atividades, praticada para enfrentar a multiplicidade de adversários. Da mesma forma, foi através do saber letrado que a Igreja Católica no Brasil redefiniu seu papel na sociedade republicana, recuperando e ampliando o poder que detinha desde os tempos coloniais. (KULESZA, 1996, p. 3-5).

A vigilância metodológica dos conteúdos parece manifestar-se com bons resultados no CNSCJ. Vejamos o texto de uma aluna publicado no Órgão das Normalistas, n. 9, 1946, 
sob o título Religião e Ciência: "A ciência, com sua esponja de aço, procura de todas as formas eliminar idéias do sobrenatural e abolir as noções de Deus". A autora refere-se aos portadores da ciência:

Levantam-se os livres-pensadores querendo criar uma sociedade moderna inculcando idéias de matéria, átomos, evolução etc. e dar assim origem a uma mentalidade sem Deus e sem religião. [...] Voltaire criou a Enciclopédia tendo por mira a destruição de Deus, dizendo que a religião é o reinado da superstição.

Os enciclopedistas não atribuíram caráter científico à religião e a acusaram de manter o povo nas pré-noções e na superstição. A normalista afirma categoricamente: "A religião não se dobra ao jugo da ciência. [...] A verdadeira ciência vem de Deus. O progresso e o desenvolvimento da ciência sã estão com a religião". A normalista teve domínio teórico dos clássicos e se posicionou firmemente contra eles. Demonstrou que a relação educativa fora bem fecunda na organização do trabalho pedagógico do colégio.

A instalação do curso no CNSCJ veio definida com a relação educativa, sob o domínio da professora, deixando-se o livro, em primeiro momento, e o cartaz, em segundo momento, em atividade subalterna.

\section{O INSTRUMENTO DO TRABALHO DIDÁTICO: O MANUAL}

O manual e, posteriormente, os murais foram utilizados na relação educativa do CNSCJ, mas, este concentrou os conteúdos do ensino nas mãos do professor. Foram os recursos intencionalmente utilizados pelas irmãs missionárias para o exercício da função cristã de bem ensinar. Prevaleceu o domínio da atividade do professor. Desde a Modernidade, os manuais didáticos haviam adquirido o domínio sobre os procedimentos pedagógicos, (HOFF, 2008, p. 8) relegando a atividade do professor, no dizer de Alves (2008, p. 3) "a uma posição subalterna na relação educativa". A organização do trabalho didático, implantada na escola por Ratke e por Comenius, tinha a intenção de baratear custos com a introdução do manual didático:

Ratke apresentou, à semelhança da divisão do trabalho material, sua proposta de divisão do trabalho didático: um único professor, com a presença de dezenas de alunos num mesmo lugar e, utilizando o mesmo instrumento de trabalho, o manual didático, ministrava o mesmo ensino a todos, na mesma hora e ao mesmo tempo. Conforme ele próprio afirmou, o ensino tornava-se mais barato, com menor custo e tempo de aprendizagem. (HOFF, 2008, p. 8).

Ao mesmo tempo, a proposta de organização do trabalho didático de Ratke e Comenius transformou o instrumento de transmissão de conhecimentos em elemento dominante nos procedimentos pedagógicos.

Ex-alunas, que freqüentaram o CNSCJ na década de 1940 a 1960, afirmaram que, antes da introdução dos murais, tudo era mais difícil: "Na época não usávamos muitos cartazes. As professoras eram quase todas estrangeiras e o método delas era expor o conteúdo, passar no quadro e, depois, explicar o livro" (Entrevistada $\mathrm{n}^{\circ} 2$; freqüentou o Curso Normal SCJ de 1951 a 1953). O instrumento do trabalho didático foi utilizado da seguinte forma, conforme a entrevistada: a professora dava textos do livro para estudar em casa e, no outro dia, o aluno tinha que expor o que entendeu do texto, examinado e emendado pela professora. O estudo e a apresentação eram individuais. Eram exigido a tal ponto que a entrevistada n. 4 (cursou o Normal entre 1962 e 1964) revelou "Era um curso

Revista HISTEDBR On-line, Campinas, número especial, p. 128-144, mai.2010 - ISSN: 1676-2584 136 
particular que o aluno fazia" O Órgão das Normalistas, n. 9, 1946 apresentou um texto, cujo título é Não tanto, irmã, revelando o aspecto pesado dos estudos e das tarefas individuais, acrescentando de forma amainada: "Nossas professoras saberão até que ponto somos capazes de fazer e dar conta de nossos deveres". A entrevistada $\mathrm{n}^{\circ} 2$ afirmou: "Era muito pesado, não era utilizado cartaz, nem gravura, nada, somente o livro e nas aulas de história e geografia era utilizado o mapa. Indicavam o autor, aí, a gente tinha que comprar o livro." As entrevistadas $\mathrm{n}^{\circ} 1,2$ e 3, não lembraram dos autores de livros, mas confirmaram os autores da época. As entrevistadas $n^{\circ} 4,5$ e 6 lembraram os livros de Maria Junqueira Schmidt e acrescentaram: "Muitos outros autores foram utilizados. Para cada disciplina os professores passavam uma série de nomes de autores que as alunas tinham que comprar. Era utilizado o livro, não tinha apostila". A ex-aluna (aluna de 19621964) acentuou que as "professoras tinham o domínio do conteúdo. Os livros desempenhavam papel complementar para as alunas. As professoras não liam o livro, elas explicavam", conformando-os aos preceitos religiosos.

A entrevistada $n^{\circ} 4$ disse que os professores leigos, contratados somente na década de 1960, recebiam das irmãs o conteúdo a lecionar. A entrevistada $\mathrm{n}^{\circ} 5$ revelou que as aulas eram expostas pelas professoras "que eram irmãs. O material utilizado eram somente livros. Todas as disciplinas tinham livros e cada disciplina tinha o seu caderno". A entrevista continuou com a ex-aluna dizendo que cada aluno tinha que fazer o seu curso, a sua preparação para o magistério: "Cada aluna tinha que providenciar o seu material. Tudo era individual. Os trabalhos, que as professoras pediam, nada era feito em grupo".

As ex-alunas lembram, também, dos murais. Afirmam que os murais eram organizados dentro das salas de aula e, também, nos corredores do colégio; eram renovados a cada semana: "cada semana era uma sala que fazia, e as professoras avaliando sempre". (Entrevista $n^{\circ}$ 5; aluna de 1951 a 1953). Pelo que se pode concluir, tratava-se de cartazes estéticos e não de cartazes didáticos. Estes surgiram na década de 1960.

O domínio do manual significaria a dominação dos métodos e conteúdos do ensino laico, legislado pelas normas nacionais e catarinenses, mediante a transmissão de conteúdos oficialmente prescritos. Para evitá-lo, as irmãs professoras requisitaram o domínio e a centralização do conhecimento para a sua função docente. As professoras, todas religiosas, mantiveram o controle do saber, centrando o trabalho didático no professor e utilizando a lição expositiva para explicar o que continha o livro. Os textos, estudados individualmente pelos alunos e apresentados em aula, estavam sob vigilância acadêmica da professora.

Por livro, não se deve entender necessariamente o manual didático; livros de autores diversos forneciam idéias e práticas escolares para os alunos do CNSCJ.

Ao analisar a relação histórica professor/educando, mediada pelo recurso didático do manual, concluímos que essa relação educativa priorizou a explicação dada pela professora em exposição oral sobre os aspectos principais do manual. Dessa forma, o manual ficou submetido à autoridade da voz e da palavra da professora. $\mathrm{O}$ instrumento do trabalho didático estava subordinado à autoridade explicativa das irmãs.

O manual - instrumento de ensino utilizado no CNSCJ, entre 1936 e 1965 - remete ao exame da relação educativa. Esta revela sua função de superar dificuldades de ordem social e religiosa na formação de professores, pois, duas ciências de referência estavam em jogo na singularidade do CNSCJ. A vigilância administrativa, realizada por leis e inspetores de ensino, dirigia uma visão laica da educação para dentro do colégio. Diferente dessa referência, sobrepunha-se a concepção de formação humana, comandada pela posição cristã das irmãs missionárias, proprietárias do estabelecimento de ensino, em 
acordo com as diretrizes dos chefes da Igreja Católica. No livro editado nos 85 anos do Colégio Sagrado Coração de Jesus, a autora escreve:

\begin{abstract}
A escola é o lugar de aprimoramento do indivíduo. [...] Não se restringia apenas aos conteúdos didáticos que eram administrados de acordo com os programas estabelecidos pelo estado, mas sim, que estes colaborassem na formação de pessoas livres, agentes de transformação que pudessem exercer suas funções no lar e na sociedade (WELTER, 2006, p. 88-9).
\end{abstract}

Quem pensa que houve divergências e conflitos entre as duas posições, não se coloca na análise dos fatos e dos documentos. A divergência não foi sentida em formas aparentes e as dificuldades práticas foram superadas rapidamente. A igreja cristã católica sempre lutou para organização o ensino em forma de educação generalista, humana e cristã. Jogou a sua força nessa luta, de bispos a leigos das comunidades católicas. No entanto, após a promulgação de determinações, normas e da legislação, a igreja aceitava as regras do jogo imediatamente. Exemplo dessa atitude foi Dom Becker, ferrenho defensor da escola privada - privada era sinônimo de confessional, naquela época - e inimigo da educação pública, laica. Em seus discursos, a adjetivação de pública e laica era acompanhada por um terceiro adjetivo: atéia. Pois, Dom Becker, na hora que o governo decretou a nacionalização do ensino, deu ordem, imediatamente, para transformar todas as escolas de língua alemã em escolas de língua portuguesa.

O CNSCJ não foi somente um lugar de aprendizagem de conhecimentos e de valores, mas ao mesmo tempo, foi um lugar em que se confrontaram duas visões de mundo, numa convivência administrada. De 1936 a 1971, a vigilância administrativa continuou a tentar eliminar da escola pública a visão cristã de mundo e toda a legislação teve o intuito de laicizar o ensino nacional. As normas governamentais impunham nitidamente uma visão laica à formação de professores, o que importou na reorganização do currículo e das disciplinas escolares e na remodelação dos conteúdos; essa visão laica também foi alimentada, sugerida e induzida pelas revistas e publicações dos renovadores da educação nova.

O estudo da relação educativa do CNSCJ revelou-se útil para entender o instrumento didático utilizado na transmissão de conhecimentos e na formação generalista, humana e cristã. Por sua vez, nas décadas de 1930 a 1960, o colégio e o Curso Normal estavam sob as determinações das disciplinas científicas, prescritas na legislação, nas normas, nos relatos de experiência e nas revistas pedagógicas oficiosas e oficiais, editadas no centro do país e na capital catarinense. No SCJ instituiu-se a norma da pedagogia laica para conduzir os alunos no entendimento dos fatos e das situações humanas, conforme a prescrição pública, mas, primou pela formação humana e religiosa. Para que isso acontecesse, o manual cedeu lugar de predominância na transmissão do conhecimento para a posição central da professora que explicava os textos, sem que o utilizasse de forma prioritária.

A utilização do manual e a prioridade da exposição oral dos conhecimentos por parte da professora deram-se até o retorno das irmãs à Suíça ou até a organização do trabalho didático realizado pelas irmãs brasileiras, após a criação da Província e após a aceitação de professoras leigas no Curso Normal.

\title{
5 A ESPECIALIZAÇÃO DO INSTRUMENTO DIDÁTICO: OS QUADROS MURAIS
}

Revista HISTEDBR On-line, Campinas, número especial, p. 128-144, mai.2010 - ISSN: 1676-2584 138 
No ano de 1965, modificou-se o instrumento de transmissão do conhecimento no CNSCJ. O papel de recurso didático na relação educativa cabia, agora, aos quadros murais - gravuras e, principalmente, cartazes.

As irmãs que pertenciam à instituição administrativa da congregação denominada Custódia, vinculada à Província colombiana, instituíram, com aval das superioras européias, uma gestão autônoma, sob o nome de Província. A fundação só foi possível devido a um crescimento numérico de irmãs brasileiras. Nesse momento, as irmãs suíças podiam optar se quisessem permanecer na nova província no Brasil ou retornar às casas religiosas da Suíça. Acrescente-se que as irmãs suíças ainda vivas estavam bem idosas e retornaram à sua pátria. A irmã Cármen Welter assumiu a direção do CNSCJ e reorganizou o trabalho didático, especificamente, introduzindo os murais, posto que o manual continuava a ser utilizado de forma complementar.

Os cartazes, além de realizar a diminuição dos custos para o colégio e para os alunos, era um instrumento flexível de transmissão de conhecimentos e permitia que o professor, elevado a uma posição de supremacia, utilizasse o aval dos autores e se tornasse a voz dominante nos assuntos tratados. Os autores escolhidos, de quem o professor extraía os conteúdos e as idéias, davam preponderância e garantia de domínio ao professor. Com a mudança do instrumento didático, a relação educativa não se alterava na essência.

Os murais foram aceitos, utilizados e comprovados eficientes, havia muito tempo. Catteeuw (2005) fez um excelente estudo sobre as "paredes que podem falar" e demonstrou seu amplo uso nas escolas belgas. Não eram novidade para as irmãs. Já eram frutos da civilização, mas foram reaproveitados intencionalmente, como uma tecnologia que ativava o trabalho didático e diminuía os custos para os alunos. Diz a entrevistada $\mathrm{n}^{\circ} 1$ : "O cartaz facilitava o ensino e o tornava mais ativo", referindo-se à simplificação do trabalho didático.

As irmãs professoras e os alunos elaboravam os cartazes. As gravuras eram compradas na Edições Melhoramentos e em outras editoras. A elaboração de cartazes não seguia apenas a técnica, assunto de uma unidade da disciplina Prática Escolar; era, também, um veículo de conteúdos da doutrina cristã. O domínio era das irmãs missionárias. O trabalho de confecção, além de seguir uma técnica específica, exigia o domínio do conhecimento dos autores escolhidos. A confecção de murais era um trabalho complexo; no entanto, a lição de aula transformava-se em trabalho simplificado. Comparado ao manual didático, o mural tinha a vantagem de ser flexível na escolha dos temas a transmitir. O cartaz era confeccionado no colégio pelas irmãs com a ajuda dos alunos, "à base da técnica. As irmãs eram muito exigentes na elaboração. A apresentação das lições em aula era feita com cartaz e gravura" (Entrevista ${ }^{\circ}$ 1, aluna de 1965-1967). Estava implícito que a boa apresentação e o conteúdo que figurava no mural era o que as irmãs consideravam a ciência de referência.

Cabe a pergunta se o quadro mural apresentava-se como uma organização do trabalho didático de cunho artesanal, visto que o professor mantinha o domínio do conhecimento e ele próprio, com o auxílio das normalistas, elaborava manualmente o cartaz. Nesse caso, se oporia à organização manufatureira do trabalho didático? A simples confecção do cartaz, porém, nada diz sobre a formação social de quem o produz e não é o elemento definidor da forma de trabalho. Todo e qualquer trabalho é complexo em seu planejamento. O que caracteriza o cartaz é a sua utilização na relação educativa, realizada em tarefas de divisão do trabalho didático.

A exigência na confecção de cartazes iniciava com o material: os cartazes estéticos - a exposição de um slogan - eram elaborados em cartolina; os cartazes didáticos - com 
itens resumidos de conteúdos escolares - eram elaborados em papel rigesa (papel próprio para embalagens). O escrito era feito com grafite, lápis de cor e pincel atômico, na sequiência do tempo. Tanto um como outro tinham a medida certa e uma metodologia específica, aprendida numa unidade do programa de Didática: "Valia nota para a aula de Didática; caso não estivesse na técnica, perdia muita nota. Tínhamos que aplicar a técnica e a metodologia dos cartazes nos estágios que fazíamos." (Entrevista n. 1).

A irmã Carmen - a primeira diretora do Curso Normal, após a fundação da Província - afirmou que ela utilizava os cartazes para motivar os alunos em sala de aula: "Eu própria confeccionava os cartazes para minhas aulas e aproveitava para ensinar os alunos que me ajudavam a elaborar e a utilizar". Ela acrescentou: "Fazer um cartaz bonito, elas faziam; mas não sabiam explorá-lo. A finalidade da aprendizagem era aprender a fazer um cartaz, a explorá-lo e aprender a metodologia".

As entrevistas de ex-alunos que freqüentaram o CNSCJ a partir de 1965 referem-se à profusão de cartazes elaborados para as lições de aula. Sobre esse assunto, inquirida, a irmã respondeu: com o retorno das irmãs missionárias para a Suíça, quando da criação da Província brasileira, o método mudou, com a introdução dos murais, gravuras e cartazes. Na transferência do Curso Normal para a Associação de caráter comunitário perderam-se os cartazes. Por falta de espaço, foi feita uma grande fogueira no colégio! - explicou a irmã.

O CNSCJ considerava a educação generalista, a erudição e a literatura aliadas necessárias. Não separava o ensino generalista e o ensino científico, a erudição e as bases científicas e se aliava aos que pensavam que o método de ensino devia agregar a erudição aos procedimentos científicos. Os pioneiros da educação nova no Brasil acentuavam os procedimentos científicos; administrativamente, as duas posições conviviam no Curso Normal do Colégio Sagrado Coração de Jesus.

\section{CONCLUSÃO}

O período em que os monopólios dominavam o Planalto Norte de Santa Catarina não proporcionou uma educação para a população. As companhias não construíram escolas nem mantinham a educação escolar para seus trabalhadores. A pequena e média produção agrícola e industrial e a imigração de alemães bucovinos, poloneses e ucranianos, efetivaram a escolarização e a formação de professores. O Colégio Sagrado Coração de Jesus das Irmãs Missionárias de Maria Auxiliadora inscreve-se neste empreendimento.

Em todos os anos de sua existência, o colégio seguiu uma proposta pedagógica própria e inserida nas normas, prescrições e nos currículos governamentais. $\mathrm{O}$ espaço para a formação generalista, de formação dos espíritos foi conquistado através do método do trabalho didático utilizado. As informações das depoentes favoreceram uma pequena reconstrução do significado do método utilizado durante os primeiros trinta anos no colégio. Trata-se do Método Celestino Benz, um pedagogo suíço que foi referência de 1936 a 1965, do qual não se conseguiu informações precisas. Tem-se, apenas, a informação de que as irmãs européias inspiraram-se na pedagogia de Celestino Benz, um método de ensino que buscava a formação humana. No entanto, quando as professoras européias retornaram à Suíça, em 1965, o método "foi com elas", porque as professoras brasileiras não o seguiram. Pelas informações colhidas, sabe-se que o pedagogo Celestino Benz era natural de Marbach, cantão de Saint Gallen. Conforme o biógrafo da madre fundadora, "graças ao método de Benz, os colégios mantidos pelas Irmãs Franciscanas Missionárias de Maria Auxiliadora na Europa, levavam vantagem sobre outros colégios e outros métodos" (MAYER. Ap. WELTER, 2006, p. 120). 
As irmãs suíças utilizavam integralmente, desde 1921, o método didático Benz no Brasil, o que já ocorrera com a congregação na Colômbia. Com a morte e as transferências das irmãs, o método deixou de ser utilizado, uma vez que as irmãs brasileiras não o assumiram. Nada se encontrou sobre esse método nos documentos, o que parece demonstrar o cuidado para registrar apenas normas oficiais.

Pelo que se pode supor, de acordo com as entrevistas, o Método Benz era tradicional, em que o instrumento do trabalho didático era o quadro-negro e o livro; o estudo e a apresentação de trabalhos dos alunos tinham o caráter individual; e o domínio do conhecimento ficava com o professor que utilizava a lição para explicar textos do livro. Havia muitas características mais no método, por enquanto não acessíveis. Tem-se, porém, a certeza de que o Método Benz centralizava a organização do trabalho didático, desde seu planejamento até sua execução, na atividade do professor, submetendo o livro a plano secundário. Essa relação educativa revela a função de superar dificuldades de ordem social e religiosa na formação de professores e de manter a vigilância metodológica dos conteúdos.

A partir do controle das irmãs brasileiras, em 1965, as lições seguiram um novo método, com amplo uso de cartazes prontos, adquiridos nas editoras, mas, principalmente, de cartazes estéticos e didáticos elaborados pelos professores e alunos na própria instituição. A prática docente tornou-se eficaz com a exposição magistral acompanhada de quadros murais, que ativavam a aula.

Catteeuw (2005, p. 256) escreve que os quadros murais têm a característica de observar as palavras escritas e as figuras correspondentes e de facilitar a tarefa do aluno que poderá intuir, entender e tomar nota. É a etapa primeira para a realização de um trabalho produzido pelo aluno.

A história escolar do Curso Normal SCJ teve esse modelo de lição. A presença do livro e, depois, do cartaz é a pista que a investigação buscou seguir para elucidar os conteúdos formativos e os conhecimentos, ministrados no curso. O termo lição designa a leitura, em voz alta, do texto, ao mesmo tempo em que o conteúdo do conhecimento é mostrado nos murais e transmitido aos alunos. Essa é a especificação do modelo pedagógico que realiza o objeto do conhecimento escolar. As lições do curso, dadas mediante o instrumento didático do livro e do cartaz, revelam a vigilância metodológica na transmissão dos conteúdos formativos do curso normal. Os conhecimentos escolares, extraídos do livro, geralmente, apresentam-se fixos e delimitados; os murais, entretanto, podem ser confeccionados com caráter flexível. À delimitação e fixidez do manual, sobrepõe-se a flexibilidade magistral ministrada com o auxílio dos murais.

Resumo de livros, o cartaz aponta para um tipo de explicação e torna-se um instrumento adequado à interpretação de teorias favoráveis, em detrimento das teorias inadequadas. É um instrumento didático barato, exigindo poucos custos. É, principalmente, um instrumento livre das amarras de um livro didático, posto que afixado nos princípios da missão da instituição religiosa.

O CNSCJ teve esse modelo de mediação dos recursos didáticos: o manual geralmente, objetivo, fixo, racional e preponderante na lição, - foi convertido em instrumento didático auxiliar, flexível, mutável e sem preponderância que foi o cartaz. Esta é a pista que a investigação buscou para elucidar a aplicação das "disciplinas científicas" obrigatórias no ensino do curso normal catarinense.

Não foi o instrumento-modelo, o manual didático, que realizou o objeto de conhecimento escolar no Curso Normal, exatamente porque, na lição, teve um papel subordinado à autoridade da professora. Dessa forma, a relação educativa realizou-se como

Revista HISTEDBR On-line, Campinas, número especial, p. 128-144, mai.2010 - ISSN: 1676-2584 141 
uma lição, com o seguinte sentido: "Evocando um modo oral de transmissão do saber, inscrito na tradição da leitura de textos em voz alta (lectio), o termo designa ao mesmo tempo o conteúdo que se torna objeto dessa transmissão." (HÉRY, 1999, p. 15). As lições, dadas em voz alta com o auxílio complementar do instrumento didático, livro ou cartaz, revelaram a vigilância metodológica na transmissão dos conteúdos formativos do CNSCJ, pois, possibilitaram a interpretação de teorias e de temas favoráveis à proposta pedagógica do colégio. Na lição, os conhecimentos escolares dos manuais, geralmente, se apresentavam conforme o domínio de referência dos renovadores da educação. À delimitação e ao enfraquecimento propositado do manual didático, sobrepôs-se, na primeira fase da organização do trabalho didático do CNSCJ, o método da autoridade magistral; e, em fase posterior, a flexibilidade e adaptabilidade dos murais, confeccionados na instituição, serviram de apoio para desenvolvimento, explicação e interpretação do tema da lição. As lições, ensinadas por meio de cartazes confeccionados, além do controle sobre os saberes escolares e da vigilância acadêmica, apresentaram-se eficazes na constituição e na transformação de saberes escolares, com menor custo para os pais dos alunos.

Em relação aos murais, as práticas reais do ensino tornaram-se facilitadas na aprendizagem e a constante troca de gravuras e cartazes no desenvolvimento da lição, davam flexibilidade à relação educativa. Enrolados em tubos próprios, as gravuras e os cartazes eram facilmente colocados na parede ou em estrado próprio. Havia a alternativa de guardar os cartazes em pé nas prateleiras. Ambas as formas de guardá-las foram comparadas aos mapas geográficos utilizados nas aulas de Geografia e de História (Entrevista n. 2).

Trata-se da feição profissional que a instituição procurou imprimir à formação de professores. O caráter científico e de aplicação prática, impresso pelos órgãos governamentais, foi contestado pelo pensamento da igreja, por trazerem no seu bojo a laicidade da educação; mas, uma vez determinado por legislação, a escola a assumiu e deu um ordenamento apropriado à relação educativa. Nesse sentido, deve-se entender o Curso Normal do Sagrado Coração de Jesus de Canoinhas: seguia rigorosamente as instruções do Decreto 306 do governo catarinense, utilizando a grade curricular e os programas impostos, mas, trabalhando-os conforme sua própria proposta pedagógica, cumprindo, dessa maneira, sua função social e religiosa.

A investigação conclui que os conhecimentos, elaborados cientificamente para se tornarem matéria de ensino, foram transmitidos, ao mesmo tempo em que o espaço da proposta pedagógica cristã foi conquistado, mediante o uso dos instrumentos do trabalho didático, escolhidos para efetivar a relação educativa. Os dois eixos de pesquisa - o livro e o cartaz, ambos subordinados à autoridade magistral, - desvelaram a função social e religiosa de uma vigilância metodológica na transmissão dos saberes escolares, visto que o uso dos instrumentos didáticos se adequou ao domínio do professor na lição. A organização do trabalho escolar, utilizando recursos técnicos de forma adequada aos objetivos, manteve a posição de supremacia da autoridade magistral, em ambas as práticas. Isso abriu o espaço para o ensino oficial e obrigatório e, ao mesmo tempo, exercia a vigilância metodológica dos saberes escolares e a valorização da cultura geral.

Os instrumentos do trabalho didático revelaram-se úteis para entendermos a forma metodológica utilizado no CNSCJ para a transmissão de conhecimentos e conteúdos formativos em sala de aula, elaborados com fins da formação generalista, humana e cristã, sendo que as determinações, prescrições e os currículos oficiais foram totalmente contemplados na prática escolar, porém, subjugados aos preceitos religiosos. Nesse 
sentido, conta a irmã Cármen: "As professoras das escolinhas da região eram reconhecidas como nossas ex-alunas pela postura e jeito de trabalhar".

\section{REFERÊNCIAS}

ALVES, G. L. (2005) O Trabalho Didático na Escola Moderna: formas históricas. Campinas, SP: Autores Associados.

ALVES, Gilberto Luiz. (2008) Instrumentos do Trabalho Didático e Relação Educativa na Escola Moderna. Campo Grande: 2008. (Programa de Pesquisa).

ARAÚJO, J. C. e outros (orgs.) (2008) As Escolas normais no Brasil. Campinas: Ed. Alínea.

ARQUIVO do Curso Normal Sagrado Coração de Jesus. Canoinhas: UnC-Canoinhas.

CANOINHAS. DOCUMENTOS AVULSOS. - 1874-1925. Assembléia Legislativa de Santa Catarina. Florianópolis: Centro de Memória, p. 9.

CATTEEUW, Karl (2005) Als de Muren Konden Spreken. Leuven: Katholieke Universiteit. Centrum voor Historische Pedagogiek.

DAROS, Maria das Dores (2002). A Sociologia na Formação dos Professores Catarinenses nos anos de 1930 a 1940. In: SCHEIBE, L; DAROS, M. D. (orgs.). Formação de Professores em Santa Catarina. Florianópolis: NUP/CED, p. 35-52.

HÉRY, Evelyne. (1999). Un Siècle de Leçons d, Histoire: la Histoire enseigné ao licée. 1879-1970. Rennes: Presses Universitaires de Rennes.

HOFF, Sandino. (1996). As Sombras e o Corpo donde procedem ou o mundo das artes como principio Educativo. Revista InterMeio. V. 2, n. 4. Campo Grande: Mestrado em Educação da UFMS. P. 4-19.

HOFF, Sandino. (2008). Apresentação. In: RATKE, Wolfgang. Escritos sobre a Nova Arte de Ensinar (1571-1635). Campinas: Autores Associados, p. 1-26.

IRMÃS Missionárias de Maria Auxiliadora. (1921-1971) Chronik der Filiale Canoinhas (Crônica da Filial de Canoinhas). Canoinhas.

JULIA, D. (2001). A Cultura como objeto histórico. Revista Brasileira de História da Educação, Campinas: Autores Associados, n.1, p. 9-43, 2001.

KULESZA, Wojciech Andrzej. (1996) Igreja e Educação na primeira República. História da Educação - GT 02. Caxambu: $19^{a}$ Reunião Anual da ANPED.

LOURENÇO FILHO. (2002). Introdução ao Estudo da Escola Nova. Rio de Janeiro: Ed. da UERJ.

NASCIMENTO, Carla Lourdes do; DANIEL, Leziany Silveira. O Instituto de Educação de Florianópolis e os Intelectuais Catarinenses na Década de 40. In: SCHEIBE, L; DAROS, M. D. (orgs.) (2002). Formação de Professores em Santa Catarina. Florianópolis. Florianópolis: NUP/CED, p.53-70.

NÓBREGA, Paulo de. Grupos Escolares: Modernização do Ensino e Poder Oligárquico. In: DALLABRIDA, Norberto. (2003) Mosaico de Escolas. Florianópolis: Cidade Futura, p. 253-280.

Revista HISTEDBR On-line, Campinas, número especial, p. 128-144, mai.2010 - ISSN: 1676-2584 143 
ÓRGÃO DAS NORMALISTAS. (1946) Canoinhas: Colégio Sagrado Coração de Jesus. Curso Normal Secundário. N. 9.

SANTA CATARINA. Decreto-lei 713, jan. 1935; Decreto 306, 1939.

TEIVE, Gladys Ghizoni. (2002) Entre o Discurso e a Prática: um olhar sobre a Escola Normal Cararinense nos anos sessenta. In: SCHEIBE, L; DAROS, M. D. (orgs.). Formação de Professores em Santa Catarina. Florianópolis: NUP/CED, p. 165-178.

WELTER, Carmen. (2006) Colégio Sagrado Coração de Jesus - 85 anos Educando. 1921-2006. Canoinhas.

www.historia.fcs.ucr.ac.cr, Acessado no dia 23 de novembro de 2008.

\footnotetext{
${ }^{1}$ Artigo reelaborado a partir da comunicação oral apresentada no VIII Seminário Nacional de Estudos e Pesquisas - Histedbr, ocorrido entre os dias 30 de junho e 03 de julho de 2009, na UNICAMP.

${ }^{2}$ Maiores informações o leitor encontra no texto A Organização do Trabalho Didático no Curso Normal do Sagrado Coração de Jesus de Canoinhas - 1936-1971, trabalho apresentado no IX Congresso Iberoamericano de História da Educação Latino-americana, ocorrido a 16-19 de novembro de 2009, no Rio de Janeiro.

${ }^{3}$ A educadora fez parte da equipe da Pedagogia Moderna na década de 1930 e foi defensora do Método Vivo (ativo) a que denomina "estágio intermédio entre o Método Direto e o Método Científico" (SCHMIDT, 1934, p. 4). Como tal na figurava na confiabilidade da cúpula eclesiástica. No entanto, décadas após, ela é aceita no colégio como educadora da Escola de Pais.
}

Artigo recebido em: 04/04/2010

Aprovado para publicação em: 21/06/2010

Revista HISTEDBR On-line, Campinas, número especial, p. 128-144, mai.2010 - ISSN: 1676-2584 